\title{
To Recycle or Not to Recycle? An Intergenerational Approach to Nuclear Fuel Cycles
}

\author{
Behnam Taebi · Jan Leen Kloosterman
}

Received: 13 September 2007 / Accepted: 22 November 2007/Published online: 13 December 2007

(C) The Author(s) 2008

\begin{abstract}
This paper approaches the choice between the open and closed nuclear fuel cycles as a matter of intergenerational justice, by revealing the value conflicts in the production of nuclear energy. The closed fuel cycle improve sustainability in terms of the supply certainty of uranium and involves less long-term radiological risks and proliferation concerns. However, it compromises short-term public health and safety and security, due to the separation of plutonium. The trade-offs in nuclear energy are reducible to a chief trade-off between the present and the future. To what extent should we take care of our produced nuclear waste and to what extent should we accept additional risks to the present generation, in order to diminish the exposure of future generation to those risks? The advocates of the open fuel cycle should explain why they are willing to transfer all the risks for a very long period of time (200,000 years) to future generations. In addition, supporters of the closed fuel cycle should underpin their acceptance of additional risks to the present generation and make the actual reduction of risk to the future plausible.
\end{abstract}

Keywords Intergenerational justice - Nuclear waste management · Reprocessing · Recycling · Future generations · Value conflicts · Sustainability

This article is a part of a research project at the Delft University of Technology, Department of Philosophy and Department of Radiation, Radionuclides and Reactors. It was also presented at the bi-annual conference of the Society for Philosophy and Technology in Charleston (South-Carolina), July 2007.

B. Taebi $(\bowtie)$

Faculty of Technology, Policy and Management, Department of Philosophy,

Delft University of Technology, P.O. Box 5015, 2600 GA Delft, The Netherlands e-mail: B.Taebi@tudelft.nl

\section{J. L. Kloosterman}

Faculty of Applied Sciences, Department of Radiation, Radionuclides and Reactors, Physics of Nuclear Reactors, Delft University of Technology, Mekelweg 15, 2629 JB Delft, The Netherlands e-mail: J.L.Kloosterman@tudelft.nl 


\section{Introduction}

The worldwide need for energy is growing. The International Energy Agency foresees a 60\% increase in energy need in the world between 2004 and 2030 and most of this expansion is expected to be met by fossil fuel [1]. Fossil fuels are not an attractive option, however, for reasons concerning the availability of resources and climate change. An increased need for alternative energy sources is therefore expected in the upcoming decades, e.g. wind energy, solar energy, but also nuclear energy. After being ruled out in many countries following the Chernobyl disaster in 1986, nuclear energy has recently made a serious comeback in the public and political debates about the future of energy. Many people consider nuclear energy at least as a serious alternative for the transition period between fossil fuels and sustainable energy sources. According to the World Nuclear Association, there were 435 operative nuclear reactors in January 2007; The United States, France, Japan and Russia together possess the vast majority of the operative reactors producing $370 \mathrm{GWe}$. As a whole, nuclear energy provides almost $16 \%$ of worldwide energy supply [2, 3].

The main advantage of nuclear energy-compared to fossil fuels-is its capability of producing a large amount of energy with relatively small amounts of fuel and a very small production of greenhouse gases. However, nuclear energy has serious drawbacks, such as accident risks, security concerns, proliferation threats, and nuclear waste. The waste problem is perhaps the Achilles' heel of nuclear energy as it remains radiotoxic for thousands of years [4].

Discussions about nuclear waste management must be related to the production of nuclear energy, as the most hazardous waste is produced during energy production. The question guiding this paper is whether spent fuel ${ }^{1}$ is to be disposed of directly or to be reused in the fuel cycle, referred to as the open and closed fuel cycle, respectively [5]. This issue is still topical after more than four decades of widely deployment of nuclear energy. In an open fuel cycle, uranium is irradiated once and the spent fuel is considered as waste to be disposed of directly. This waste remains radiotoxic for approximately 200,000 years; the period in which the radiotoxicity of spent fuel will equal that of the amount of natural uranium used to produce the fuel. Radiotoxicity is defined as the biological impact of radioactive nuclides on human health, in case they are digested or inhaled; these effects are indicated in sievert (Sv) or millisieverts $(\mathrm{mSv})$. The closed fuel cycle reuses spent fuel after irradiation to produce energy and diminishes its toxicity and volume substantially. This fuel cycle has many long-term benefits, but it also creates extra short-term risks.

The question rises here how to deal with spent fuel in a proper way, taking the needs and interests of this generation and future generations into account. We should not foreclose options for future generations and should manage the waste in a such way that "will not impose undue burdens on future generations" [6, 7]. In this paper we approach "undue burdens" in the light of fuel cycles and propose intergenerational justice as a framework in order to choose between the fuel cycle: are we willing to transfer all risks of spent fuel to future generations, or do we find it

\footnotetext{
${ }^{1}$ For the sake of consistency, we here refer to the irradiated fuel in a nuclear reactor as spent fuel rather than waste.
} 
more just to diminish risks and hazards of our waste to the maximum extent and accept, consequently, some additional risks to the present generation. We discuss the idea of having right towards future generation and the concept of intergenerational justice. We further present the two fuel cycles and identify the associated risks with these fuel cycles. In the following chapter, we focus on conflicting values in choosing between them and reduce all trade-offs to a chief trade-off between the present and future generations. The next chapter provides a few underlying assumptions and possible counter-arguments.

Whether nuclear energy is desirable or indispensable as an energy source in the future is a controversial issue, which is beyond the scope of this paper. At the same time, applying nuclear energy through different fuel cycles raises a number of ethical concerns and moral dilemmas; on those issues we focus here. Moreover, the existing spent fuel all around the world is an urgent problem that needs to be dealt with. 280,000 tons of spent fuel had been discharged globally by the end of 2004, of which one-third has been recycled, leaving 190,000 tons of spent fuel stored; the growth rate is estimated on 10,500 tons a year [8,9]. The choice between the open and closed fuel cycle has significant influence on this growth. These intergenerational discussions are also crucial for the future of research investments on waste management issues. Partitioning and transmutation (P\&T) is a new technology for further diminishing the waste radiotoxicity. $\mathrm{P} \& \mathrm{~T}$ is still in its infancy and needs serious investments to be further developed $[10,11]$; these investment are justified if and only if one chooses the closed fuel cycle, of which the P\&T could be considered as an extension.

\section{Future Rights, Present Obligations: Intergenerational Justice}

Increasing concerns about depleting the Earth's resources and damaging the environment have invoked a new debate on justice across generations or intergenerational justice. This concept of justice was first introduced by John Rawls in 1971 as intergenerational distributive justice, which stands for an equal allocation of social benefits and burdens [12]. Justice for future implies that today's people have obligations towards their descendants [13, 14] and these obligations entail certain rights for the future [15-17]. These assumed rights have been challenged by some philosophers: "...the ascription of rights is probably to be made to actual persons-not possible persons" [18] and non-existing future people cannot be said to have rights, as our action and inaction define their composition and identity [19]; this is referred to as the Derek Parfit's 'non-identity-problem'. Other objections against these alleged rights are expressed as the inability to predict future properly, the ignorance of the need and desire for future as well as the contingent nature of future. There have been a variety of arguments provided in the literature to these objections ${ }^{2}$ [20-23]: William Grey has proposed "impersonal principles

\footnotetext{
${ }^{2}$ For an extensive discussion on future obligations and rights, see Justice Between Age Groups and Generations, ed. Laslett and Fishkin, Sharder-Frechette's Environmental justice Creating Equality, Reclaiming Democracy, Avner de-Shalit's Why Posterity Matters, Environmental policy and future Generations and Justice, Posterity and the Environment, ed. Beckerman and Pasek (all mentioned in the bibliography).
} 
subject to retroactive person-affecting constraints" [24] and Wilfred Beckerman has argued that we should provide future people with the minimum opportunity for a "decent and civilised society" [25].

Although these fundamental discussions about right and obligation towards future people are very relevant, in this paper we will focus on the application of these assumed future rights to environmental policy and more specifically nuclear waste. In the last decades the climate change has given rise to serious concerns for the future [26, 27]. Do we have a duty to future generations [21, chap. 5] and if so what does this duty entail [28] and how should we realize it [29]?

Anticipating technological progress in a rapidly developing world and being concerned about future generations, the World Commission of Environment and Development introduced the concept of sustainable development in 1987. This moment designates the introduction of intergenerational concerns in environmental policy. This Brundtland definition—named after commission's chairperson—states that the key to sustainable development is an equitable sharing of benefits and burdens between generations "[...] that meets the needs of the present without compromising the ability of future generations to meet their own needs" [30]. The United Nations Conference on Environment and Development in Rio de Janeiro in 1992 (Earth Summit) not only endorsed this concept of sustainable development formally among 178 national governments, it also explicitly included the concept of equity in its principles [31, Principle 3].

The sustainability principle implies that there is a conflict of interest between the present and future generations. In an anthology edited by Andrew Dobson, the concept of sustainable development is evaluated in the light of intergenerational justice [32]. Wilfred Beckerman believes that the problems future people encounter have existed for millennia and states that our main obligation towards future people is "moving towards just institution and a 'decent' society", which encompasses future generations as well [33, p. 91]. Brian Barry investigates whether sustainability is a "necessary or a sufficient condition of intergenerational distributive justice". Barry emphasizes the obligations we have towards future generations and says that "measures intended to improve the prospects of future generations [...] do not represent optional benevolence on our part but are demanded by elementary considerations of justice" $[34,35]^{3}$. Bryan Norton perceives of sustainability as "an obligation not to diminish the opportunity of future generations to achieve wellbeing at least equal to their predecessors." He further presents a model in order to compare well-being across time [36]. The "contested meaning of sustainability" in technology is comprehensively discussed by Aidan Davison [37].

What does the forgoing discussion about rights and obligations entail for nuclear fuel cycles, considering the fact that spent fuel life-time concerns a period between 1,000 and 200,000 years? The Nuclear Energy Agency (NEA ${ }^{4}$ ) introduces sustainability in one of its studies [11]. In this paper we adapt this definition both conceptually and practically and introduce intergenerational justice as a framework

\footnotetext{
${ }^{3}$ First published in Theoria in 1997 and 2 years later in Dobson's anthology Fairness and Futurity.

${ }^{4}$ NEA is a specialized agency of the OECD (Organization for Economic Co-operation and Development).
} 
to choose between the fuel cycles. Intergenerational concerns have already been expressed about nuclear waste [38-40], but mainly with respect to the choice for final disposal of long living radioactive waste.

\section{Nuclear Fuel Cycles: Open and Close}

The characteristic difference in the fuel cycles is how spent fuel is dealt with after irradiation. Two main approaches to spent fuel outline the main dissimilarity between these cycles: (1) the direct isolation of the material from the environment for a long period of time in which it remains radiotoxic and (2) 'destroying' or converting the very long-lived radionuclides to shorter lived material [5]. The first approach represents the open fuel cycle in the production of energy. The closed fuel cycle is in accordance with the second approach. Here below we will elaborate on these two fuel cycles.

\section{Open Fuel Cycle (OFC): Once-through Option}

In the OFC, the lesser isotope of uranium $\left({ }^{235} \mathrm{U}\right)$ is fissioned-split-in light water reactors (LWR) to produce energy; $90 \%$ of all operative nuclear reactors to produce energy are LWRs. Natural uranium contains two main isotopes, which constitute ${ }^{235} \mathrm{U}$ and ${ }^{238} \mathrm{U}$. Only the first isotope $\left({ }^{235} \mathrm{U}\right)$ is fissile and is used in LWRs as fuel, but it only constitutes $0.7 \%$ of natural uranium. This low concentration is not sufficient in nuclear reactors, the concentration of ${ }^{235} \mathrm{U}$ is therefore deliberately enhanced to a minimum of $3 \%$ through a process called uranium enrichment [4].

Irradiating uranium produces other materials, including plutonium $\left({ }^{239} \mathrm{Pu}\right)$, which is a very long-lived radioactive isotope. Apart from plutonium-239, other fissile and non-fissile plutonium isotopes as well as minor actinides will be formed during irradiation. Actinides are elements with similar chemical properties: uranium and plutonium are the major constituents in spent fuel and are called major actinides; neptunium $(\mathrm{Np})$, americium $(\mathrm{Am})$, and curium $(\mathrm{Cm})$ are produced in much smaller quantities and are called minor actinides. The presence of actinides in spent fuel defines the radiotoxicity and waste life-time. The OFC is also called the once-through strategy, as the spent fuel does not undergo any further treatment.

The spent nuclear fuel in an OFC will be disposed of underground for 200,000 years. This waste life-time in an OFC is dominated by plutonium. Neither minor actinides nor fission products have a significant influence on long-term radiotoxicity of waste in an OFC. Figure 1 illustrates these radiotoxicities. The dashed line represents spent fuel in an OFC, decaying to the ore level in approximately 200,000 years. Fission products are a mixture of various radionuclides that will decay to the uranium ore level after approximately 300 years [41], indicated by the dotted line in Fig. 1. 


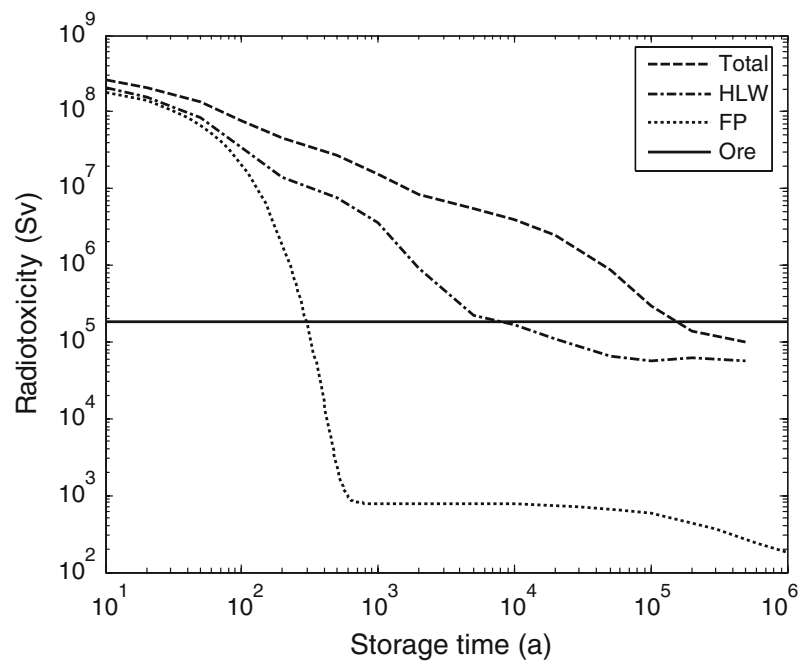

Fig. 1 Radiotoxicity of spent fuel, vitrified waste (HLW) and fission products, compared with regard to the radiotoxicity of uranium ore needed to manufacture the fuel

\section{Closed Fuel Cycle: Recycling Plutonium and Uranium}

As stated above, less than $1 \%$ of the uranium ore consists of the fissile isotope ${ }^{235} \mathrm{U}$. The major isotope of uranium $\left({ }^{238} \mathrm{U}\right)$ is non-fissile and needs to be converted to a fissile material for energy production: plutonium $\left({ }^{239} \mathrm{Pu}\right)$. Spent fuel could undergo a chemical treatment to separate fissionable elements including $\mathrm{Pu}$, this is referred to as reprocessing. During reprocessing, uranium and plutonium in the spent fuel are isolated and recovered. Recycled uranium could either be added to the front-end of the fuel cycle or used to produce mixed oxide fuel (MOX), a mixture of uraniumoxide and plutonium-oxide that can be applied in nuclear reactors as a fuel [42] (see Fig. 2). Reprocessing is also called the "washing machine" for nuclear fuel. The irradiated fuel is "washed and cleaned" and "clean" materials $(\mathrm{U}+\mathrm{Pu})$ are reinserted into the fuel cycle to produce more energy, while the "dirt" is left behind (fission products and minor actinides) to be disposed of as high level waste (HLW) [4]. HLW contains fission products and minor actinides and will be put into a glass matrix in order to immobilize it and make it suitable for transportation, storage and disposal. This process is called conditioning of waste and results in so-called vitrified waste [6]. The ultimate radiotoxicity of vitrified waste will decrease to the uranium level in approximately 5,000 years [41], as illustrated by the dashed-dotted line in Fig. 1.

As uranium and plutonium are separated and reused, this fuel cycle is called the closed fuel cycle. The choice for a CFC is rightly associated with the choice to recycle spent fuel. Figure 2 illustrates various steps in both nuclear fuel cycles and their different interpretations of spent fuel. As can be seen in Fig. 2, the solid line representing the OFC is a once-through line. The CFC on the contrary is illustrated by separating plutonium and uranium and returning them to the fuel cycle, 


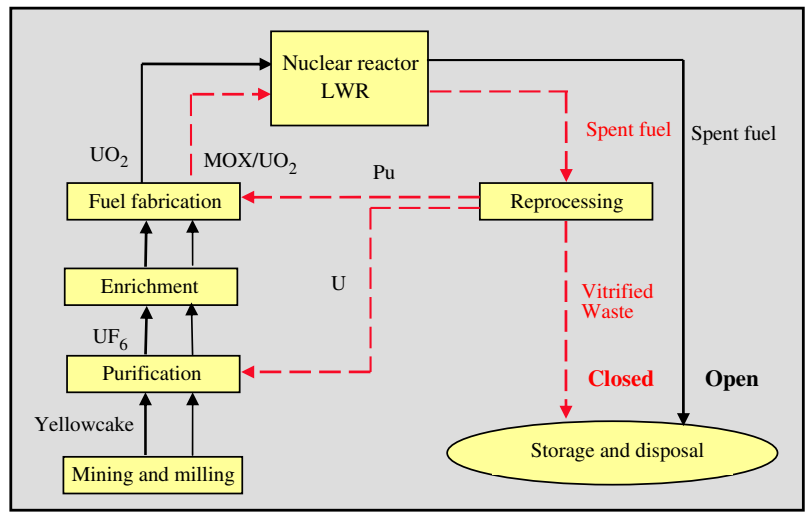

Fig. 2 An overview of the open and closed nuclear fuel cycle; the solid lines represent the OFC, the dashed lines the CFC

represented by the dashed lines. Nowadays, the main objective of reprocessing is to use uranium more efficiently and to reduce the waste volume and its toxicity considerably.

In the CFC, one can distinguish between two options with respect to nuclear reactors. In the first option, conventional LWRs are used, which are capable of using MOX as fuel. Reprocessed spent fuel is returned to the fuel cycle as MOX. Spent MOX fuel could again be reprocessed to separate uranium and plutonium. Further recycling of plutonium is only possible in another type of reactor capable of handling non-fissile plutonium: fast reactors, which constitute the second option. In the second option, the latter are basically used as energy producing reactors, in which MOX is the fuel. Due to the fast neutrons, fast reactors are capable of using the major isotope of uranium $\left({ }^{238} \mathrm{U}\right)$ to the maximum extent via conversion to ${ }^{239} \mathrm{Pu}$ [43].

The Future of the Closed Fuel Cycle; Maximal Recycling

As spent fuel is conceived of as the Achilles' heel of nuclear energy, there have been serious attempts to further reduce its radiotoxicity and volume. A new method is partitioning and transmutation (P\&T), which could be considered as a recent supplementary method to reprocessing. Spent fuel comprises uranium and plutonium, minor actinides and fission products. Uranium and plutonium are separated during reprocessing in order to reuse; P\&T focuses on "destroying" minor actinides in spent fuel. If completely successful, $P \& T$ is expected to reduce the volume and radiotoxicity of spent fuel one hundred times (compared to OFC). After P\&T, fuel radiotoxicity would decay to a non-hazardous level in 500 to 1,000 years [10]. The waste stream would then only consist of relatively short-lived fission products and curium isotopes. The latter will dominate the waste life-time and are considered to be too hazardous to be recycled at reasonable expenses and risks. P\&T 
is merely available at the laboratory level at the moment; a considerable amount of $R \& D$ efforts is needed, before P\&T could be utilized industrially $[10,11]$.

\section{Waste Management, Interim Storage, Long-term Storage and Repositories}

Irrespective of the fuel cycle choice, the remaining waste in a nuclear reactor after the (optional) treatments needs to be disposed. In waste management, a distinction is made between storage and disposal: storage means keeping the waste in engineered facilities aboveground or at some ten of meters depth underground, while disposal is the isolation and emplacement of the waste at significant depth (a few hundreds of meters) underground in engineered facilities, called 'geological repositories'

Until now, all the available storage facilities for spent fuel and high level waste have typically been above ground or at very shallow depth. Spent fuel is mostly stored under water for at least 3-5 years after removal from the reactor core; this stage is called interim storage. Water serves as radiation shielding and cooling fluid [39]. Bunn argued that interim storage for a period of 30-50 years has become an implicit consensus, as the world's reprocessing capacity is much less than globally spent fuel generation. In addition, there are no final repositories at our disposal yet. Interim storage of waste is also a crucial element in the safe management of radiotoxic waste since waste should be stored to allow radioactive decay to reduce the level of radiation and heat generation before final disposal. For the countries that favor reprocessing, spent fuel remains available for some decades to be reprocessed and there is no need to build up vast stockpiles of separated plutonium after reprocessing. For countries supporting direct disposal of spent fuel, interim storage allows more time to analyze and develop geological repositories appropriately [44].

A commonly proposed alternative to geological disposal is the long term monitored storage on the surface. Spent fuel remains in this case retrievable in the future. However, the technical community appears largely to disregard this option and considers the surface storage only as an interim measure until the waste can be disposed of in geological repositories [5, 38, 39, 45]. Deep oceans and outer space are mentioned as possible locations for final disposal as well, but there are substantial political, ethical as well as technical impediments, mainly related to the safety of these locations [5].

\section{Risks and Associated Values}

In this paper we distinguish moral values at play in the production of nuclear energy. Values are what one tries to achieve and strives for, as we consider them valuable; moral values refer to a good life and a good society. However, we should not confuse them with people's personal interest; moral values are general convictions and beliefs that people consider as worth striving for, in public interest [46]. We further identify dilemmas and moral problems rising from conflicting values: some trade-offs need to be made in order to choose a fuel cycle. The three main values we distinguished are as follows: sustainability, public health and safety 
and security. In the following sections we try to specify these values and, for the sake of comparison, relate them to risks and benefits of the open and closed fuel cycle.

We here distinguish between short-term and long-term effects, in which we consider the upcoming 50 years as short-term and after that as long-term. This period is chosen in view of comparisons in the literature between the fuel cycles: strong views about maintaining the OFC are mainly about the coming five decades [47] and in economic comparisons, short-term is defined as 50 years [48], probably based on estimations of reasonably assured uranium sources for the coming five to six decades in 2002 [49]. To conclude, 50 years is the period in which supply certainty of the OFC is assured. However, as will be shown later on, this period can be extended to 85 years or more without invalidating the arguments and conclusions of this paper.

\section{Sustainability: Supply Certainty, Environmental Friendliness and Cost} Affordability

A comparative study of the Nuclear Energy Agency (NEA) on various P\&T technologies introduces the following three axes in order to assess sustainability: (1) resource efficiency (2) environmental friendliness and (3) cost effectiveness [11]. In this paper we take these axes as a guideline for understanding sustainability with respect to nuclear energy and follow an adapted version in terms of concepts and terminology, with regard to the fuel cycles.

\section{Supply Certainty}

On the first axis, sustainability refers to the continued availability of uranium: NEA uses the term resource efficiency for this. In this paper we apply the term supply certainty instead. Deploying resources efficiently means that we aspire to use as less as possible resources for the same purpose, while supply certainty refers to availability of resources in order to fulfill the needs. In energy discussion, certainty is a more significant concept than efficiency. Although this difference in designation has no consequences for the factual comparison in availability of uranium, we prefer the conceptually correct term.

As there are 50-60 years of reasonably assured uranium resources [49], there will be no significant short-term influences of the fuel cycle on the supply certainty. Later estimations of the NEA and the IAEA $^{5}$ present approximately 85 years of reasonably assured resources (RAR) uranium are available for a once-through option in a LWR. These institutions estimate that this amount suffices for 2,500 years in a CFC, based on a pure fast reactor cycle, which is an improvement

\footnotetext{
5 The International Atomic and Energy Agency (IAEA) is the World's central intergovernmental forum for scientific and technical cooperation in nuclear field. IAEA is a specialized agency of the United Nations.
} 
in supply certainty with a factor 30 [50]. Two later reports of the IAEA in 2006 adjust this period to 5,000-6,000 years, assuming that fast breeders allow essentially all non-fissile ${ }^{238} \mathrm{U}$ to be bred to ${ }^{239} \mathrm{Pu}$ in order to be used as fuel [8, 51]. It needs to be mentioned that these estimations are made under the explicit assumptions that fast breeders will be broadly deployed in the future.

The supply certainty benefits of the CFC will be relevant in the long run. Although there are no short-term significant differences between the fuel cycles, countries without natural fossil fuel, like Japan and France, tend to opt for reprocessing and recycling [52].

\section{Environmental Friendliness: Radiological Risks to the Environment}

The second axis of the OECD approach in specifying sustainability concerns environmental friendliness. This value depends on the accompanying radiological risks to the environment. Radiological risks, as we perceive them in this paper, express the possibility or rather probability that spent fuel leaks to the biosphere and can harm both people and the environment.

The NEA proposes three stages to assess radiological risks: (1) mining and milling, (2) power production, and (3) reprocessing. They compare the radiological risks of the OFC with the (once) recycled and reused MOX fuel. In the power production phase, NEA argues, there is no difference between the cycles. The main difference lies in the two other steps: mining and milling and reprocessing. They further argue that deployment of reprocessing decreases the need for enriched uranium and, therefore, natural uranium, of which the mining and milling involve the same radiological risks as reprocessing and reusing plutonium as MOX fuel. In fact, NEA argues that under the described circumstances there are equal radiological risks for both fuel cycles [53]. This argument is probably sound in the long run, for large scale reprocessing enterprises and under ideal circumstances, but one can wonder whether the factual short-term consequences are such that radiological risks of both fuel cycles are quite similar. The question remains whether we should take comparisons under ideal circumstances or factual consequences into consideration (in moral discussions). Furthermore, NEA completely neglects the distribution of benefits and burdens: building a reprocessing plant in France will increase local risks to the surrounding area and will diminish the burdens in a uranium-exporting country, such as Canada.

NEA further neglects the risks and hazards associated with the transport of waste in case of reprocessing: "...[R]adiological impacts of transportation are small compared to the total impact and to the dominant stage of the fuel cycle" [53]. If we consider different aspects of public perception of risk, we cannot retain the idea that radiological risks of nuclear waste transportation are negligibly small [54]. Only a few reprocessing plants are currently available around the world and spent fuel needs to be transported to those plants and back to the country of origin. In GreatBritain, for instance, a serious debate is currently taking place about the possibilities to return Japanese reprocessed spent fuel to Japan. 


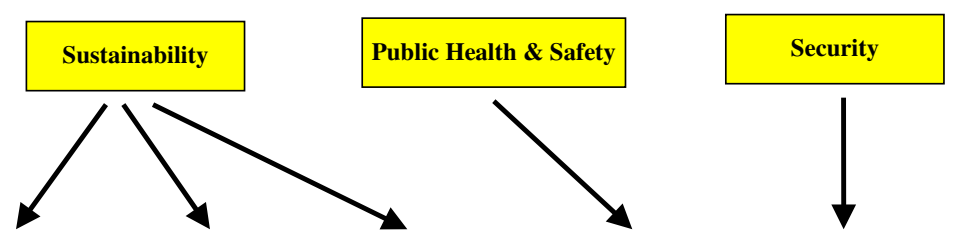

\begin{tabular}{|c|c|c|c|c|c|c|c|c|c|c|}
\hline & \multicolumn{2}{|c|}{ Supply certainty } & \multicolumn{2}{|c|}{$\begin{array}{c}\text { Radiological risks } \\
\text { to environment }\end{array}$} & \multicolumn{2}{|c|}{ Affordability } & \multicolumn{2}{|c|}{$\begin{array}{l}\text { Radiological } \\
\text { risks to public }\end{array}$} & \multicolumn{2}{|c|}{ Proliferation } \\
\hline & Short & Long & Short & Long & Short & Long & Short & Long & Short & Long \\
\hline Open & + & - & + & - & + & - & + & - & + & - \\
\hline Closed & + & + & - & + & - & + & - & + & - & + \\
\hline
\end{tabular}

Fig. 3 Ethical values (first row) and their specification (second row) related to the OFC and CFC. A plus sign represent an improvement of the ethical value and has a positive connotation, a minus sign is a drawback of the value

One of the serious counterarguments against reprocessing is the large investments needed to build the plants; small countries with a few nuclear power plants and in favor of the CFC will probably not build a reprocessing plant and will keep transporting spent fuel to those countries capable of this technology. To illustrate, The Netherlands is one of the countries with favorable reprocessing policy: Dutch spent fuel is currently transported to La Hague (France). There is no real chance that The Netherlands will build its own reprocessing plant in the coming years. To conclude, we assume that reprocessing will result in more short-term radiological risks, both to the environment and to the public health and safety, as illustrated in Fig. 3.

The short-term and long-term effects mentioned above also pertain to environmental friendliness. Using the fuel to the maximum extent and maximally recycling the spent fuel could be considered as long-term 'environmentally friendly', as the environment is less exposed to potential radiological risks and radiotoxicity in the long run. One of the main arguments in favor of reprocessing - along with enhanced resource efficiency - is the vast reduction of waste volume and its toxicity and the accompanying advantages from a sustainability point of view. The volume of each ton of spent fuel containing approximately $1.5 \mathrm{~m}^{3}$ of HLW could be reduced through reprocessing three times [55]. The waste toxicity will decrease at least with a factor three [52].

\section{Affordability}

The third axis the NEA proposes in its comparison is cost effectiveness. We adapt this axis here into affordability. We acknowledge the relevance of economic aspects for initiation and continuing a technological activity. Sustainability can be conceived of as durability, to that purpose. However, economic effectiveness goes much further than the question whether an activity is reasonably durable or 
affordable. Social security is, for instance, mostly ineffective economically but we consider that as a duty of the state with respect to its citizens; nevertheless, it is supposed to be neither economically effective nor profitable.

It is also arguable whether durability should be accepted as sustainability. This is an ongoing debate about different interpretations of the notion of sustainability. In a moral discussion, it is probably more just to separate economic considerations from other aspect of sustainability. However, for the sake of our analysis we follow here NEA's analysis and accept sustainability conceived as durability.

In 1994, a NEA study determined a slight cost difference between the reprocessing option and direct disposal. Based on best estimates and the uranium prices of that time, the cost of direct disposal was approximately $10 \%$ lower, which was considered to be insignificant, taking the cost uncertainties into account [56]. However, considering later uranium prices and resource estimations, there is a strong economic preference for the once-through strategy, even if a considerable growth of nuclear energy production is anticipated [52]. A MIT study in 2003 on 'The Future of Nuclear power' upholds the same view on economic aspects of reprocessing. Deutch et al. conclude in this report that-under certain assumptions and the US conditions - the CFC will be four times as expensive as the OFC. The once-through option could only be competitive to recycling if the uranium prices increase [47]. These MIT researchers are not susceptible to the counterarguments that disposing of reprocessed HLW will be less expensive. They furthermore present a cost model in which reprocessing remains uneconomic, even if the cost of reprocessed HLW were zero [47]. Another international study compares reprocessing with the once-through option and concludes that-even with substantial growth in nuclear power-the open LWR fuel cycle is likely to remain significantly cheaper than recycling in either LWRs (as MOX) or fast breeders for at least the next 50 years [48].

In the previous reasoning we considered reprocessing as a broadly applied technology, which will create the need to build new reprocessing plants. Economic affordability appear totally different if we base our analysis on the existing reprocessing plants, as many small consumers of nuclear energy reprocess their spent fuel in France or Great-Britain. These countries do not have excessive initial expenditures for their CFC.

\section{Public Health and Safety: Short-term and Long-term Radiological Risks}

The second value is public health and safety. We again distinguish between shortterm and long-term radiological risks, which cause hazards to public health and safety. Recycling of plutonium as MOX diminishes the eventual radiotoxicity of spent fuel with a factor three, assuming that spent MOX fuel is disposed of after one use (also called once-through recycling ${ }^{6}$ ). Theoretically, multiple recycling of plutonium in fast reactors can decrease the long term radiotoxicity of disposed waste

\footnotetext{
$\overline{{ }^{6}}$ Not to be confused with the once-through option or the OFC.
} 
by a factor 10 . These scientific achievements could be brought into practice in several decades [52].

Recycling spent fuel includes the separation and storage of plutonium. Along with security arguments which will be discussed later, plutonium contains serious potential risks to the public health due to its exceptional toxic nature. Plutonium needs especial isolation from humans, as it contains long-lived alpha emitters, which are very radiotoxic upon inhalation [57, p. 113)]. We included these risks in the short-term radiological risk for waste treatment. With respect to long-term radiological risks, the same reasoning as for the previously mentioned sustainability holds true: the short-term radiological risks associated with the $\mathrm{CFC}$ are significantly higher than the OFC.

\section{Security and Proliferation Hazards}

The last, but certainly not least value at play in waste management is security as a result of production of plutonium during recycling. Concerns regarding nuclear weapon proliferation are extremely relevant given the current state of world security. Proliferation threats rise either by the use of enriched uranium (up to 70\%) or by the production or separation of plutonium. To illustrate, eight kilograms of weapon grade plutonium $\left({ }^{239} \mathrm{Pu}\right)$ are sufficient to produce a Nagasaki-type bomb [58].

Proliferation is also a potential hazard in countries capable of enriching uranium. One of the main tasks of the IAEA is to annually report to the United Nation's Security Council about nuclear energy possessing nations. Although both the OFC and the $\mathrm{CFC}$ need enriched uranium in the reactor, the short-term proliferation concerns of the CFC are considerably higher, due to the separation of plutonium during reprocessing.

The security concerns are double-edged: reprocessing increases proliferation concerns for the contemporary people, but at the same time it decreases those concerns for future generations, since the spent fuel residuals contain no plutonium any more. One can argue that the potential proliferation concerns of direct disposal of spent fuel in the OFC are negligible compared to the actual security concerns in case of reprocessing: disposed spent fuel cannot be retrieved unnoted, and expensive and inaccessible reprocessing plants are needed to separate plutonium from it for weapon manufacturing. Some scholars argue, on the other hand, that spent fuel in geological repositories becomes a better weapon-grade material as time goes by, due to the natural enrichment of ${ }^{239} \mathrm{Pu}$ [10]. However, this effect will take place in several thousands of years. In sum, the CFC involves more short-term proliferation and security concerns but decreases those concerns in the long run, as illustrated in Fig. 3.

\section{Value Conflicts in Fuel Cycles and Future Generations}

In the preceding analysis, we formulated a number of values and aimed to translate risks and benefits of the fuel cycles into these values. In decision-making about the 
fuel cycles we are confronted with a number of value conflicts. It should be mentioned that the plus and minus signs in Fig. 3 are merely approximations which enable us to make a comparison between the OFC and CFC, these signs are neither quantitative measures nor absolute entities. It should further be mentioned that plusses represent an improvement in terms of the three basic values, illustrated in squares on top of Fig. 3; minuses are drawbacks of these values.

\section{Value Conflicts}

In choosing between options, we have to accept certain trade-offs between these basic values. The CFC enhances sustainability in terms of supply certainty and creates less radiological risks to the environment. It also diminishes public health and safety concerns, as well as security concerns in the long run. At the same time, however, the CFC involves more short-term additional risks and, therefore, compromises public health and safety as well as security of contemporary people. It also deteriorates short-term sustainability, perceived as environmental friendliness. Trading off these conflicting values in a certain way can help one choose one of the fuel cycles. To illustrate, if one holds the cleanness of the environment we bequeath to our descendants as most important, she should be willing to accept some additional risks to the public in the present and, therefore, the CFC would appear the obvious choice. Short-term risks are traded off against the long-term benefits in the CFC. Another example: if one considers proliferation threats in the current security state of the world highly unacceptable, she trades off long-term benefits of the CFC against the short-term benefits of the OFC; the latter will be the outcome of this trade-off.

In the literature, implicit trade-offs are made. A MIT study in 2003 concluded unambiguously that the once-through fuel cycle is the best choice for the US for at least 50 years. MIT researchers asserted that the reprocessing plants in Europe, Russia, and Japan involve unwarranted proliferation risks and did not believe that benefits of the CFC outweigh the safety, environmental and security risks as well as economic costs [47]. Von Hippel upheld the same view on reprocessing: proliferation and economic costs of reprocessing are high and the environmental benefits are questionable. He maintained that direct storage of spent fuel after irradiation is cheaper, safer and more environmentally benign than reprocessing [59].

Proliferation of nuclear weapons is one of the main concerns in the discussions about recycling nuclear waste. IAEA director El-Baradei noted in 2004: "We should consider limitations on the production of new nuclear material through enrichment and reprocessing, possibly by agreeing to restrict these operations to being exclusively under multinational control" [60]. Proliferation concerns with respect to reprocessing are the main reason why many countries prefer the OFC. The US, Sweden, Finland, and Canada have chosen the OFC to avoid plutonium separation. But unlike these countries, reprocessing occurs in many European countries such as Great-Britain and France as well as smaller nuclear energy consumers like The Netherlands, that reprocesses its nuclear waste in the French plants in La Hague. 
There are serious attempts to make reprocessing proliferation-resistant, including the US global nuclear energy partnership (GNEP) and the Russian Federation's global nuclear power infrastructure initiatives [8].

\section{Intergenerational Justice and Nuclear Waste Management}

One of the key principles of radioactive waste management laid down by the IAEA in 1995 is that it should be managed in such a way that it "will not impose undue burdens on future generations" [6]. This principle is founded on ethical consideration that the generation enjoying the benefits of an undertaking should manage the resulting waste. The NEA supported this definition in the same year in a collective opinion [7].

As illustrated, the CFC mostly has long-term benefits and compromises public health and safety as well as security of the contemporary people. Does the aim to avoid "undue burdens on future generations" mean that we are supposed to diminish waste radiotoxicity and its volume as much as possible? To what extent should we accept the increased risks and hazards to the present generation in order to accomplish the latter?

The questions how to interpret the "undue burden" can best be understood within the framework of intergenerational justice. Especially in fundamental policy decision-making, the question rises how one generation could equitably take the interest of future generations into account. Serious discussions about this issue started in the US [61] and are still ongoing in nuclear communities in choosing between options for final disposal of waste $[38,39]$. Some scholars interpreted the NEA collective opinion in 1995 as a confirmation for the-once and for all-sealed underground repositories. Uncertainty in long-term safety and possible future needs to recover plutonium (from spent fuel) for its potential energy value are two serious objections to permanently closed repositories [62]; we are after all required not to deprive future generations of any significant option [6, 7]. Inequity of risks and benefits across generations are two other reasons opposing permanent disposal [63]. In other words, scholars argue that permanent disposal forecloses options to future generations to retrieve and reverse waste. Alternatives to permanent disposal are long-term continued surface storage or phased repositories, which remain open for an extended period of time. There seems to be consensus among nuclear experts that disposal in repositories should be given preference above surface storage, as it is believed to be a passively safe solution that does not require burden of care by future generations [38].

In a recent European study, Schneider et al. argue that the main concerns in risk governance are the transfer of a whole waste management system, including a safety heritage, from the present to the future generations [64]. They approach various technical and societal issues, such as long-term responsibility, justice and democracy from the perspective of generations, both across generations and within one generation.

In this paper we propose to reduce the trade-offs in choosing the fuel cycle to a chief trade-off between the present and the future. Is it legitimate and just to transfer 
all the risks and hazards of nuclear waste to future generations? How can we arrange an equitable transfer of the whole waste management system-as argued by Schneider et al.- - to the future? Or is it more just and equitable to handle our waste as much as possible, in order to diminish its risks in the far future?

The OFC is to be associated with short-term benefits and the CFC primarily has long-term benefits ${ }^{7}$. In this reasoning, accepting the CFC means that we intend to diminish the risks and hazards to the future and accept some additional risks for the present generation. The OFC transfers the risks as much as possible to the future and avoid those risks in the present.

\section{Underlying Assumptions and Possible Counter-arguments}

So far we have argued that decision-making on the fuel cycles could best take place within the framework of intergenerational justice. This conclusion is based on the analysis in the foregoing chapter, in which we illustrated the choice between the OFC and the CFC mainly as a choice between the present and future generations. Obviously, there are a few assumptions at the basis of this analysis. Below, we will discuss some of these underlying assumptions and provide some possible counterarguments and evaluate their validity.

\section{Defining Short-term as 50 years}

In our analysis, we defined short-term as 50 years. Beyond half a century we considered as long-term. The question that rises here is whether 50 years constitute the real turning point in comparing the specified values, as we introduced in Fig. 3. And more importantly, will other distinctions in time spans between short and longterm change our conclusion? As we mentioned earlier, the period of 50 years was taken from the comparisons we found in the literature. Most scholars preferring the OFC, pronounce their strong opinion for the coming five decades and economic comparisons are made for this period of time [47, 48]. Both mentioned studies based their strong opinion on estimations of reasonably assured uranium resources at the beginning of this century; NEA and IAEA considered this amount in 2001 enough for 50-60 years [49]. This period is, however, extended to 85 years in the 2005 estimations (of IAEA and NEA). It needs to be mentioned that the bulk of this increase is not due to discovering more resources, but it is a result of re-evaluation of previous resources in the light of the effects of higher uranium prices [50].

Looking at the first columns in Fig. 3 (supply certainty), the long-term benefits of the CFC will not change if we take 85 years as a turning point, the long-term benefits of supply certainty in the CFC will come into practice after this period. We should mention here that we founded our analysis on the identified resources. The total undiscovered resources of uranium are expected to be significantly higher [50].

\footnotetext{
${ }^{7}$ One exception to this trade-off is supply certainty that shows no significant difference between the fuel cycles.
} 
If we base our analysis on the latter, the long-term benefits of the CFC will probably vanish entirely, even for a much longer period of time. However, an analysis based on undiscovered resources comprises such an amount of uncertainty that estimations are practically meaningless.

Whether the column affordability will change, if we consider short-term as being 85 years, is not clear. We can state that high initial investments for the reprocessing plant might perhaps be affordable, if we consider a longer period of time. However, there have been no serious estimations based on the announced reasonably assured uranium resources in 2005 .

\section{All Released Pu will Eventually be 'Destroyed'}

Beneficial long-term radiological risks of the $\mathrm{CFC}$ are based on the assumption that all plutonium is separated from spent fuel and "destroyed". As plutonium is the dominant element in indicating the waste life-time in spent fuel, its extraction from waste will diminishes waste radiotoxicity substantially. The mentioned period of radiotoxicity of vitrified waste after reprocessing of 5,000 years [41], includes the assumption of complete consumption of plutonium after separation. Less long-term proliferation hazards in the CFC are also based on the same assumption: extracted plutonium is ultimately fissioned. How realistic is this assumption if we consider the millions of kilograms weapon-grade plutonium and highly enriches uranium (to above $70 \%$ ) discharged as a result of dismantlement of warheads after the Cold War?

These released materials could also either be considered as waste to be disposed of directly or as potential fuel for the production of energy. These different points of view mark the divergent approaches between the two superpowers in the Cold War. Americans believe that excess plutonium has no economic value, as it costs more to use as energy source than the energy is worth. However, since the other option of dealing with this hazardous material, i.e. its disposal, is costly as well, some plutonium is supposed to be used as reactor fuel (MOX), but only in a once-through scenario. This is perfectly in line with the American concerns about (civilian) plutonium which is not recycled and reused either. Russians hold a totally different view on this issue: they consider excess weapon plutonium as fuel having "significant energy potentials". Russia also acts in accordance with their CFC perspectives. However, they believe-together with Americans-that the potential value of these plutonium stockpiles cannot be cashed in the near future, as it needs substantial additional costs [58].

Plutonium has already proven its benefit in the production of energy. Reprocessed plutonium from civil reactors is called civilian plutonium, a name that could mistakenly be understood as unfeasible weapon material (although it is very unfavorable as a weapon material). As reprocessing of plutonium has outpaced its use as fuel and due to technical and regulatory restrictions, no more than $30 \%$ of produced MOX could be fissioned in a reactor, which creates an imbalance between separated civil plutonium and reused MOX; in the beginning of this century an estimated amount of 200 tons of civilian plutonium was available in the 
stockpiles [52]. This amount is vastly growing and is believed to surpass the total amount of released weapon plutonium soon. Referring to the theft concern and concerns on excessive surpluses of plutonium, mainly in former Soviet Union countries, Bunn et al. argue for an international phased-in moratorium on reprocessing [58, 65].

Irrespective of Bunn's reasoning's validity regarding nuclear theft, we can easily state that separated plutonium for the purpose of reprocessing contains more proliferation concerns than plutonium 'embedded' in spent fuel. The latter needs advanced and very expensive technology to separate plutonium, which is not accessible outside the legal authorized and controlled way of the IAEA, which supports the argument that separated plutonium involves more security and proliferation concerns.

A similar reasoning holds true for the toxic properties of plutonium. If we extract plutonium from spent fuel, under the assumption that it will eventually be fissioned and, consequently, prevent it of being disposed of underground, we create de facto more risks for the contemporary people. These risks were already included as more short-term radiological risks in Fig. 3. However, if we fail to make it plausible that extracted plutonium will eventually be fissioned in reactors as MOX, we merely create more risks - both short-term and long-term-and that will substantially change our analysis. Considering the fact that one-third of separated plutonium is currently fissioned through reprocessing, the long-term benefits of the $\mathrm{CFC}$ will merely be meaningful under the assumption that MOX consumption will substantially expand.

The latter is possible under two scenarios: (1) broader deployment of MOX fuel and (2) less reprocessing, as produced MOX could first be consumed. Less deployment of reprocessing conflicts with the initial assumption. We were trying to give underpinnings for long-term benefits of the CFC, of which reprocessing is a crucial component. That leaves the first scenario open: less long-term risks of the CFC are plausible if and only if we take a wider deployment of MOX fuel for granted, either as a result of adapting existing reactors or due to a broader application of MOX in the planned reactors or reactors being built. According to the World Nuclear Association, there are 28 new reactors being built and 64 are ordered or planned worldwide. Furthermore, there are 158 reactors proposed and waiting for funding or approval [2]. These developments can give support to the long-term benefits of the CFC. Still, the protagonists need to make plausible that the stockpiles of civilian plutonium extracted through reprocessing will eventually be fissioned.

\section{How Long does the 'Long-term' Last in Case of Radiological Risks?}

Let's go back to the first assumption discussed with respect to defined time spans in order to distinguish between the short-term and long-term. So far, we argued that the $\mathrm{CFC}$ has less long-term radiological risks, assuming that separated plutonium in reprocessing will eventually be fissioned. However, these radiological benefits will be noticeable only after 5,000 years, which represents the waste life-time of 
reprocessed waste (vitrified waste). After 50 years the $\mathrm{CFC}$ creates more additional risks to both public and the environment (at that moment), the more so since reprocessing will be an ongoing business in the CFC.

The question raises here whether this challenges our analysis. The trade-offs needs still to be made between the short-term and long-term radiological risks. The CFC is rightly associated with less long-term risks: perceived from now or after 50 years, there will be less long-term risks in remote future. The analysis is still valid, but these long-term benefits will reveal after a much longer period of time than the proposed 50 years for supply certainty. To sum up, 50 years is not applicable to all comparisons, but the line of analysis will not change as a consequence.

\section{The CFC and the Transition Period}

Let's now take a look at the argument of nuclear energy being used in a transition period between conventional fuel resources (fossil fuel) and sustainable energy, from the perspective of the CFC. As we stated earlier, based on the 2004 nuclear energy consumption, the uranium resources are available for a period of approximately 85 years for a once-through option in a LWR [50]. There is also no economic reason for deployment of the CFC in the upcoming 50 years, as it remains uneconomic for this "short" period of time and the high initial investments cannot be recovered, even if a considerable growth of nuclear energy is anticipated $[47,48,52]$. So far we argued that the benefits of the CFC will be revealed in the long run only, certainly in no less than 50 years. If this time exceeds the transition period, should those who believe in nuclear energy to bridge the transition period, be consequentially in favor of the OFC?

This transition period is not accurately defined in the literature; it concerns the transition of fossil fuel to sustainable energy sources. Nuclear energy is believed to play a significant part into this transition until 2020, due to its assured supply certainty and low emissions [66]. Which role nuclear energy will play after this period depends on developments in tackling safety, waste and proliferation issues. Most advocates of the transition-period argument do not exclude nuclear energy: they believe that nuclear energy is capable of being sustainable in the future, if the afore-mentioned concerns are being taken care of [66].

If we agree that the CFC is-under some assumptions-more environmentally benign in the long run and if the latter is the outcome of our trade-offs, we can argue that we should use the CFC for the transition period, no matter how short or how long this period is. The long-term burdens as a result of nuclear energy deployment will be there anyway, the CFC enables one to diminish those burdens to some extent. There are also no technical restrictions to deployment of the CFC in short periods of time, except the time needed to build a reprocessing plant. However, the argument we presented with respect to actually destroying plutonium holds stronger if one is in favor of applying nuclear energy to bridge a transition period: within that same period, all plutonium should then be destroyed. 
Choosing Between OFC and CFC. Is not that a False Dilemma?

In our analysis we presented two different methods in the production of nuclear energy. Prior to our analysis, we stated that the questions with respect to desirability of nuclear energy will be beyond the scope of our paper. We also listed the state-ofthe-art in the production of nuclear energy, being responsible for $16 \%$ of world's energy production, and focused on existing moral conflicts. Under these assumptions, there are two methods to produce nuclear energy, namely the OFC and the CFC.

The question raises here whether there will be a third fundamentally different option, or in other words, whether the choice between the OFC and the CFC is a false dilemma? Future developments of nuclear energy mainly concern effort to reduce radiotoxicity of waste, such as the $\mathrm{P} \& \mathrm{~T}$ presented in this paper. These options are to be considered as an extended CFC and are not essentially different. We still need to deal with the trade-offs as we described in this paper.

One can further argue that the framework of intergenerational justice can give rise to unacceptable risks in both scenarios. In other words, the intergenerational justice framework refutes both nuclear fuel cycles. Such reasoning challenge the assumptions we made with regard to nuclear energy rather than our analysis based on those assumptions.

\section{Why do not we Talk about Justice Among Contemporaries?}

In the preceding chapters we argued that the choice for a fuel cycle should be made within the framework of intergenerational justice. In other words, we should (also) take the needs and interest of future generations into consideration and make a trade-offs between the latter and the interest of contemporary people, in order to make a decision on the fuel cycle. The question rises here: is that a sufficient condition? Especially when we consider that the majority of nuclear plants is located in developed countries, while more than $30 \%$ of the world's uranium production is coming from developing countries [50]. Kazakhstan, Uzbekistan, Namibia, and Niger that are bearing the burdens of the front-end of the fuel cycle (i.e. milling, mining, etc.) do not have a power plant at all and will not be able to share the benefits of nuclear energy? Is not this a relevant question, perceived from distributive justice?

The authors fully acknowledge the relevance of evaluating justice among contemporaries in this discussion, which is referred to in the literature as intragenerational justice. However, intragenerational considerations are not decisive in the choice for the fuel cycle, they rather follow from the choice one makes. To illustrate, when a country decides to deploy the CFC, the question rises where the country is going to reprocess its waste; is it just that Dutch waste-for instance-goes to La Hague in France to be reprocessed? These intergenerational justice considerations are also relevant within a country: is it just that the Nevadans bear the burden of the whole American waste which probably will be disposed off under the Yucca Mountains in Nevada. Similar considerations are to be made in 
case of locating a nuclear power plant: people in the direct vicinity bear the burdens, while the whole nation enjoys the benefits.

As we briefly showed here, intragenerational considerations rather challenge the assumption we made in the beginning of this paper with regard to the deployment of nuclear energy, than to help us to make a choice between the fuel cycles. Intergenerational justice, however, offers a suitable framework for choosing the fuel cycle. Once this choice is made, intragenerational concerns are born.

\section{Conclusions}

In this paper we evaluate NEA's definition for sustainability [11] and adapt that definition both conceptually and practically: it is questionable-from a moral standpoint - whether sustainability can be related to economic issues and it is more correct to use economic affordability instead of cost effectiveness. We further argue that though sustainability - as defined by NEA and adapted here-is a crucial aspect in this discussion, it does not offer a proper basis to choose a fuel cycle: public health and safety as well as security concerns are at least as important to be included. By adding a time dimension to this comparison, we propose a new framework in order to choose the nuclear fuel cycle-intergenerational justice-and specify consequences of both fuel cycles within this new framework. To that purpose, we identify values at play and value conflicts one encounters in choosing between the fuel cycles: the CFC improves sustainability in terms of the availability of fuel and involves less radiological risks to the public and the environment in the long run, but it compromises public health and safety in the present. The CFC also poses serious security threats for the contemporary people, due to the production and the separation of plutonium. However, at the same time it diminishes those threats for future generations.

These trade-offs in nuclear energy are reducible to a chief trade-off between the present and the future. To what extent should we recycle our produced nuclear waste in order to avoid "undue burdens" on the future and to what extent should we accept additional risks for the present generation? These questions can be answered within the proposed framework of intergenerational justice. This concept of justice is often used in the nuclear discussions, mainly to tackle issues with respect to final waste disposal, waste retrievability in the future and, more recently, risk governance with regard to the question how we can equitably transfer a whole waste management system to the future.

In our analysis we used lots of estimations with regard to uranium resources, waste radiotoxicity and the radiological risks of the waste. How valid are these estimations if we include the uncertainties encompassing our analysis? Estimations and predictions are the key problems in dealing with the future, especially when we talk about the remote future. These uncertainties need to be further investigated in future studies in order to test the validity of provided analysis. It is also recommendable to quantify the probabilities of these risks in order to compare them in a more appropriate way. Do the decreased risks to the public and the environment in the remote future equal the increased risks to the present generation? 
In this paper, we approach the choice between the fuel cycles perceived form the perspective of intergenerational justice. Advocates of he OFC should argue why they are willing to transfer all the risks for a very long period of time (200,000 years) to future generations and accept all the accompanying uncertainties for their descendants. Supporters of the CFC should underpin their acceptance of additional risks to the present generation. More importantly, they should make it plausible that separated plutonium during reprocessing is eventually "destroyed". Proliferation remains the leitmotiv in these discussions, as it is the main objection against the CFC.

Open Access This article is distributed under the terms of the Creative Commons Attribution Noncommercial License which permits any noncommercial use, distribution, and reproduction in any medium, provided the original author(s) and source are credited.

\section{References}

1. IEA. (2004). World energy outlook. International Energy Agency.

2. WNA. (2007). World nuclear power reactors 2006-07 and uranium requirements, information paper. World Nuclear Association.

3. IAEA. (2007). Nuclear technology review. in Report by the Director General.

4. Cochran, R. G., \& Tsoulfanidis, N. (1999). The nuclear fuel cycle; analysis and management (2nd ed., pp. 381). La Grange Park, Illinois USA: American Nuclear Society.

5. IAEA. (2000). Radioactive waste management-turning options into solutions. Vienna: IAEA 3rd Scientific Forum.

6. IAEA. (1995). The principles of radioactive waste management, in radioactive waste safety standards programme. Vienna: (RADWASS) Safety Series 111-F. IAEA.

7. NEA-OECD. (1995). Environmental and ethical basis of geological disposal of long-lived radioactive wastes: a collective opinion of the radioactive waste management committee of the OECD nuclear energy agency. Nuclear Energy Agency, Organisation for Economic Co-operation and Development.

8. IAEA. (2006). Annual report. Vienna: IAEA.

9. McCombie, C., \& Chapman, N. (2002). Regional and international repositories: Not if, but when. World Nuclear Association Annual Symposium.

10. KASAM. (2005). Partitioning, transmutation-an alternative to final disposal. An issue in focus (chapter 8 in nuclear waste-state-of-the art reports 2004). In H. Condé, et al. (Eds.), Stockholm, Sweden: National Council for Nuclear Waste (KASAM).

11. NEA-OECD. (2002). Accelerator-driven systems (ADS) and fast reactors (FR) in advanced nuclear fuel cycles: a comparative study. Nuclear Energy Agency, Organisation for Economic Co-operation and Development.

12. Rawls, J. (1971). A theory of justice (pp. 7-11). Oxford University Press.

13. Schwartz, T. (1978). Obligations to posterity. In I. Sikora, \& B. Barry (Eds.), Obligations to future generations (pp. 3-13). Philadelphia: Temple University Press.

14. Callahan, D. (1981). What obligations do we have to future generations? In E. Partridge (Ed.), What do we owe posterity? (pp. 73-88). New York, Buffalo: Prometheus Books.

15. Baier, A. (1981). The rights of past and future persons. In E. Partridge (Ed.), Responsibilities to future generations (pp. 171-183). Buffalo, New York: Promoethus Books.

16. De George, R. (1981). The environment, rights, and future generations in responsibilities to future generations: environmental ethics. In E. Partridge (Ed.), (pp. 157-166). Buffalo, New York: Promethus Books.

17. Feinberg, J. (1974). The rights of animals and unborn generations. In W. Blackstone (Ed.), Philosophy and environmental crisis (pp. 43-68).

18. Macklin, R. (1981). Can future generations correctly be said to have rights? In E. Partridge (Ed.), Responsibilities to future generations: environmental ethics (pp. 151-156). Buffalo, New York: Promethus Books. 
19. Parfit, D. (1983). Energy policy and the further further: the identity problem. In D. MacLean, \& P. G. Brown (Eds.), Energy and the future (pp. 166-179). Totowa, New Jersey: Rowman and Littlefield.

20. P. Laslett, \& J. S. Fishkin (Eds.) (1992). Justice between age groups and generations. Yale University Press.

21. Shrader-Frechette, K. (2002). Environmental justice: creating equality, reclaiming democracy. environmental ethics and science policy series. Oxford: Oxford University Press, pp. 269.

22. De-Shalit, A. (1995). Why posterity matters: environmental policies and future generations. London, New York: Routledge.

23. Beckerman, W., \& Pasek, J. (2001). Justice, posterity, and the environment. New York: Oxford University Press.

24. Grey, W. (1996). Possible persons and the problems of posterity. Environmental Values, 5(2), 161179.

25. Beckerman, W. (1997). Debate: intergenerational equity and the environment. Journal of Political Philosophy, 5(4), 392-405.

26. Page, E. (1999). Intergenerational justice and climate change. Political Studies, 47(1), 53-66.

27. Meyer, L. H., \& Roser, D. (2006). Distributive justice and climate change. The allocation of emission rights. Analyse \& Kritik, 28, 241-267.

28. Gosseries, A. (2001). What do we owe the next generation (s)? Loyola of Los Angeles Law Review, 35(1), 293-354.

29. Gardiner, S. M. (2003). The pure intergenerational problem (1). The Monist, 86(3), 481-501.

30. Brundlandt, G. H. (1987). Our Common Future. Report of the World Commission on Sustainable Development. UN, Geneva, 208.

31. UN. (1992). Rio declaration on environment and development, in United Nations conference on environment and development. Rio de Janeiro.

32. Dobson, A. (1999). Fairness and futurity: essays on environmental sustainability and social justice. New York: Oxford University Press.

33. Beckerman, W. (1999). Sustainable development and our obligations to future generations. In A. Dobson (Ed.), Fairness and futurity: essays on environmental sustainability and social justice (pp. 71-92). New York: Oxford University Press.

34. Barry, B. (1999). Sustainability and intergenerational justice. In A. Dobson (Ed.), Fairness and futurity: essays on environmental sustainability and social justice (pp. 93-117). New York: Oxford University Press.

35. Barry, B. (1997). Sustainability and intergenerational justice. Theoria, 45(89), 43-65.

36. Norton, B. (1999). Ecology and opportunity: intergenerational equity and sustainable options. In A. Dobson (Ed.), Fairness and futurity: essays on environmental sustainability and social justice (pp. 118-151). New York: Oxford University Press.

37. Davison, A. (2001). Technology and the contested meaning of sustainability. Albany: New York State of University of New York Press.

38. NEA-OECD. (1999). Progress towards geologic disposal of radioactive waste: where do we stand? In An International Assessment. Paris: Nuclear Energy Agency, Organisation for Economic Cooperation and Development.

39. IAEA. (2003). The long term storage of radioactive waste: safety and sustainability. In A Position Paper of International Experts. Vienna: IAEA.

40. KASAM. (2005). Nuclear waste, ethics and responsibility for future generations (chapter 9 in nuclear waste- state-of-the art reports 2004), M. Stenmark, \& C. R. Brakenhielm (Eds.), Sweden, Stockholm: National Council for Nuclear Waste (KASAM).

41. NEA-OECD. (1996). Radioactive waste management in perspective. Paris: Nuclear Energy Agency, Organisation for Economic Co-operation and Development.

42. Wilson, P. D. (1996). The nuclear fuel cycle; from ore to wastes. Oxford: Oxford University Press, pp. 323.

43. van Rooijen, W. F. G., Improving fuel cycle design and safety characteristics of a gas cooled fast reactor 2006, PhD Thesis TU-Delft, The Netherlands: Delft.

44. Bunn, M.e.a. (2001). Interim storage of spent nuclear fuel. Managing the Atom Project, Harvard University, Cambridge, MA, and Project on Sociotechnics of Nuclear Energy, University of Tokyo.

45. NEA-OECD. (1999). Geological disposal of radioactive waste-review of developments in the last decade. Paris: Nuclear Energy Agency, Organisation for Economic Co-operation and Development.

46. Royakkers, L. M. M., van de Poel, I., \& Pieters, A. (2004). Ethiek \& Techniek. Morele overwegingen in de ingenieurspraktijk. Baarn, The Netherlands: HB uitgevers. 
47. Deutch, J. \& Moniz, E. J. (2003). The future of nuclear power: an interdisciplinary MIT study. Massachusetts Institute of Technology.

48. Bunn, M., et al. (2003). The economics of reprocessing versus direct disposal of spent nuclear fuel. Belfer Center for Science and International Affairs, John F. Kennedy School of Government, Harvard University.

49. IAEA-NEA. (2002). Uranium 2001: Resources, production and demand. In A joint report by the OECD nuclear energy agency and the international atomic and energy agency. Paris: IAEA and NEA-OECD.

50. IAEA-NEA. (2006). Uranium 2005: resources, production and demand. In A joint report by the OECD Nuclear Energy Agency and the International Atomic and Energy Agency. Paris: IAEA and NEA-OECD.

51. IAEA. (2006). Nuclear power and sustainable development. Vienna: IAEA, pp. 39.

52. Bertel, E., \& Wilmer, P. (2003). Whither the nuclear fuel cycle? Nuclear Energy, 42(3), $149-156$.

53. NEA-OECD. (2000). Radiation protection radiological impacts of spent nuclear fuel management options: A comparative study, in OECD Nuclear Energy. Nuclear Energy Agency, Organisation for Economic Co-operation and Development, pp. 1-126.

54. Slovic, P., Flynn, J. H., \& Layman, M. (1991). Perceived risk, trust, and the politics of nuclear waste. Science, 254(5038), 1603.

55. NEA-OECD. (20001). Trends in the nuclear fuel cycle: economic, environmental and social aspects. Nuclear Energy Agency, Organisation for Economic Co-operation and Development.

56. NEA-OECD. (1994). The economics of the nuclear fuel cycle. Nuclear Energy Agency, Organisation for Economic Co-operation and Development.

57. Cooper, J. R., Sokhi, R. S., \& Randle, K. (2003). Radioactive releases in the environment: impact and assessment. West Sussex, England: John Wiley and Sons, Ltd.

58. Bunn, M. (2000). The next wave: urgently needed new steps to control warheads and fissile material. Carnegie Non-Proliferation Project, Carnegie Endowment for International Peace; Harvard Project on Managing the Atom, Belfer Center for Science and International Affairs, Harvard University.

59. von Hippel, F. N. (2001). ENERGY: plutonium and reprocessing of spent nuclear fuel. 293(5539), 2397-2398.

60. El-Baradei, M. (2004). Nuclear non-proliferation: global security in a rapidly changing world. Washington, DC: speech, Carnegie International Non-proliferation Conference, pp. 21.

61. NAPA. (1997). Deciding for the future: balancing risks, costs, and benefits fairly across generations, in A report for the U.S. Department of Energy. National Academy of Public Administration USA.

62. NRC. (2001). Disposition of high-level waste and spent nuclear fuel: The continuing societal and technical challenges, B.o.R. W. M. Committee on Disposition of High-Level Radioactive Waste Through Geological Isolation, Editor. National Research Council (NRC), p. 212.

63. Shrader-Frechette, K. S. (1993). Burying uncertainty: risk and the case against geological disposal of nuclear waste. University of California Press.

64. COWAM, Long term governance for radioactive waste management. Final Report of COWAM2Work Package 4, in COWAM2-D4-12, CEPN - R - 301, T. Schneider, C. Schieber, \& S. Lavelle (Eds.) 2006, COWAM, p. 53.

65. Bunn, M., et al., Securing nuclear weapons and materials: Seven steps for immediate action. 2002: Project on Managing the Atom, Belfer Center for Science and International Affairs, John F. Kennedy School of Government, Harvard University; Co-published by Nuclear Threat Initiative.

66. Bruggink, J. J. C., \& van Zwaan, B. C. C. (2002). The role of nuclear energy in establishing sustainable energy paths. International Journal of Global Energy Issues, 18(2), 151-180. 